\title{
SPONTANEOUS RUPTURE OF RENAL PELVIS
}

\section{AFTER RENAL TRANSPLANTATION}

\author{
BARRY A. KOGAN, M.D. \\ JOHN W. KONNAK, M.D. \\ ROBERT J. MACGREGOR, M.D. \\ DARRELL A. CAMPBELL, JR., M.D. \\ From the Sections of Urology and General Surgery, Department of Surgery, \\ University of Michigan Medical Center, Ann Arbor, Michigan
}

\begin{abstract}
Spontaneous rupture of the renal pelvis occurred in 4 cases following renal transplantation. The diagnosis was difficult, and all 4 patients were septic at the time of treatment. Three patients survived, but preservation of the transplant was possible in only 1 case. The cause is uncertain but may be related to functional obstruction or vascular insufficiency.
\end{abstract}

Urinary extravasation occurred in 31 of 585 renal transplants performed at the University of Michigan Medical Center, and of these, 4 suffered spontaneous rupture of the renal pelvis. Previously, this complication has been reported only rarely, therefore, a review of the diagnosis, treatment, outcome, and possible origin of this complication appeared warranted. Our experience is contrasted with that reported for spontaneous rupture of the renal pelvis in the general population and that reported for urinary fistulas after renal transplantation.

\section{Material and Methods}

Table $I$ is a summary of the clinical data in our 4 cases. Extravasation from the renal pelvis occurred in 1 cadaver and 3 living related recipients. It developed from five to forty-six days post-transplant and was noted in patients who had undergone ureteroureterostomy, transvesical ureteroneocystostomy, and external ureteroneocystostomy using the techniques described by Freier et al. ${ }^{1}$ The exact diagnosis was not made preoperatively in any case. Treatment was transplant nephrectomy in 2 cases, repair and drainage of the renal pelvis in 1 , and pyelostomy in the fourth. Although 3 patients survived, graft preservation was possible in only 1 case.

\section{Comment}

The diagnosis of rupture of the renal pelvis was elusive in all 4 cases, as evidenced by the delay of from six to thirty-five days from onset of symptoms until treatment. In 2 cases a wound infection was the initial abnormality noted. Later this developed into an obvious urinary fistula, requiring surgical exploration. In the other 2 patients acute peritonitis developed as a result of transperitoneal rupture of an infected urinoma. Again, surgical exploration was required. Despite the use of excretory urography, ultrasonography, and nuclear scanning, the site of extravasation was not identified preoperatively in any case. Retrograde pyelography is difficult after ureteroneocystostomy especially when an external urcteroneocystostomy technique is used. Antegrade pyelography is not performed safely unless the renal pelvis is dilated. Dilatation was not present in any of the cases and is unlikely after rupture. Diagnosis is dependent on a high index of suspicion. When clinical judgment suggests operative intervention, a careful inspection of the renal pelvis should be included.

All the patients in the group under consideration were ill at the time of presentation. In 2 cases (Cases 1 and 1 ), the septic status of the patient required that transplant nephrectomy be 
Table 1. Clinical data

\begin{tabular}{|c|c|c|c|c|}
\hline & $-\cdots-\frac{}{1}-\cdots$ & - Calse & -- & 4 \\
\hline $\operatorname{Ag} e^{+} i \mathrm{r}$ & 26 & 25 & 23 & is \\
\hline $\operatorname{sex}$ & Mate & Male. & Male. & Fomale \\
\hline Vo. of tritmsplants & 1 & 2 & 2 & I \\
\hline Domor & I ivinger related & l.iring. rolated & Cadaver & I is ins. rolated \\
\hline $\begin{array}{l}\text { Time from tramsplant } \\
\text { to presentation }\end{array}$ & 5 days & 5 day & $4 f$ days & tians \\
\hline Time from presentation & & & & \\
\hline to treatment & 35 dans & 7 days & 24 days & is dials \\
\hline Vo of remal arteries & 1 & 1 & 2 & 1 \\
\hline Creteral amatcimosis & $\begin{array}{l}\text { External ureteromero- } \\
\text { eystostomy }\end{array}$ & $\begin{array}{l}\text { Extermal ureteromere } \\
\text { cystostomy }\end{array}$ & $\begin{array}{l}\text { l.ardbetter-Politano } \\
\text { mreteroureterostony }\end{array}$ & $\begin{array}{l}\text { Leadibetter-Politano } \\
\text { ureteroureterostomy }\end{array}$ \\
\hline Presentation & Peritonitis & Peritonitis & I'rinary fistula & Crinary fistula \\
\hline Treatunent & $\begin{array}{l}\text { Tramplant } \\
\text { nephrectomy }\end{array}$ & $\begin{array}{l}\text { Repair and } \\
\text { nephrostom! }\end{array}$ & Pyelostomy & $\begin{array}{l}\text { Transplant } \\
\text { nephrectomy }\end{array}$ \\
\hline ()istrome. & $\begin{array}{l}\text { Alive on } \\
\text { dialysis }\end{array}$ & $\begin{array}{l}\text { Vormal renal } \\
\text { function }\end{array}$ & Died & $\begin{array}{l}\text { Alive ont } \\
\text { diatysis }\end{array}$ \\
\hline
\end{tabular}

performed. Both patients made an uneventful recovery. In 1 patient (Case 3) the tramsplant wits left in place, a pyelostomy performed, and immunosuppression continued; this patient died of progressive sepsis. The fourth patient (Case 2) also presented with septic symptoms. He was treated with extensive drainage of the retroperitoneal space, and the kidney was left in situ. Immunosuppression was temporarily withdrawn, and the patient's sepsis was reversed. Subsequently. low doses of immunosuppressive diugs were atministered followed by repair of the renal pelvis and nephrostomy drainage. Because there was a 2-haplotype match between the sibling clonor and recipient, normal transplant function was preserved, and the patient made an uneventful recovery.

The origin of this complication was not clearly elucidated in any case. No mechanical obstruction occurred in our patients. and no major vascular injury could be implicated. All patients in the series were infected at the time of treatment. but it is impossible to determine if this wats the caluse or the result of the extravasation. Several other theories may explain this occurrence but are difficult to document. Functional obstruction mat have played a role in 3 cases. Case 3 had the visual appearance of an acquired ureteropelvic junction obstruction at the time of surgical exploration. Two other patients (Cases 1 and 2) had a brisk diuresis $(300-1,000 \mathrm{cc} / \mathrm{hr}$.) in the immediate postoperative period. Because of the edema and decreased peristalsis at the ureteral anastomosis, the urine output mas have exceeded the capacity of the collecting srstem. creating a finctional obstruction and high intrapelvic pressures. This is impossible to document retrospectively. Another theory would be that there was interference with the blood supply to the renal pelvis. This is unlikely since the renal pelvis has a rich capillary blood supply and there was no dissection of the renal pelvis. and in particular, no dissection near the transverse artery at the pyelocortical junction. ${ }^{2}$ Perhaps high intrapelvic pressures maty decrease capillary blood fow in the renal pelvis. The fact that 3 patients who received kidney's from living related donors had the onset of simptoms four to five days post-transplantation is suggestive of a rascular origin, but there is no explanation of why the renal pelvis and not the ureter was affected in our cases. The role of rejection and or poor healing due to immunosuppression is also impossible to document.

Several reports of ruptures of the remal pelvis in the general population have been presented. Abeshouse reviewed the literiatur. on this subject in 1935. His article rematios a definitive work on this subject. He noted that most cases are traumatic and those which are "spontaneous" usually occur in an abnormal upper urinary tract. Predisposing factors include infections of the renal pelvis, hydronephrosis. obstruction. and instrumentation of the urinary tract. Symptoms and signs are varied and range from local irritation of nearby gastrointestinal organs to generalized sepsis. Although this was the preantibiotic era, prognosis varied directly with time until diagnosis and treatment. Repair and drainage, drainage alone, and nephrectomy have all been employed successfully depending on the clinical circumstances. 
Several authors have also addressed the topic of urinary fistulats after renal transplantation. ${ }^{4-6}$ Infection, poor healing in the immunosuppressed host and crrors in techniques of harvesting or transplantation are believed to be responsible for most catses. Vascular insufficiency and ureteral necrosis is an end result in many cases. Symptoms and signs are varied. but a mass overlying the kidney and wound drainage are often seen. Early diagnosis and prompt institution of therapy is emphasized by all anthors. Depending on the clinical circumstances, therapy may be nephrectomy, drainage and repair, or observation.

Spontaneous rupture of the renal pelvis after renal transplantation has been mentioned only three times in the literature. ${ }^{4,7.8}$ The diagnosis was made only after considerable urinary extravasation had resulted in a fluctuant mass. Treatment consisted of successful repair, attempted repair followed by nephrectomy, and transplant nephrectomy. The authors believed that the rupture was secondary to obstruction of the ureteroneocystostomy in 1 case and to erosion of an infected hematoma in another.

Our data suggest that this complication, while unusual, is more common than previously appreciated (4 cases in 585). The diagnosis is often delayed, and as a consequence the patient will often show signs of systemic sepsis. Adequate debridement and tensionless reapproxi- mation of the renal pelvis is not always feasible. Transplant nephrectomy is the treatment of choice in most cases. However, the clinical condition of each patient is different, and an occasional graft may be salvaged if the patient is clinically well or if the degree of histocompatibility is such that immunosuppression can be dramatically reduced.

Urology Section Box 03 University Hospital 1405 E. Ann Street

Ann Arbor, Michigan 48103

(DR. KONNAK)

\section{References}

1. Freier DT, et al: Remal transplantation, in, kendall AR and Karafin L. (Eds): Urology, Hagerstown. Harper and Row Pulblishers, 1980 . dhap. 27. p. 1.

2. Sporer A and Sectorde JJ: Study of the renal blood supply and its implication in renal pelvic surgery, Urology 17: 18 (19881).

3. Abeshouse BS: Rupture of the kidney pelvis, Surg. Gynecol. Obstet. 60: 710)(1935)

4. Salvatierra O Jr. et al: Urologic complications of renal transplantation can be prevented or controlled, J. Urol. 117: $421(1977)$.

5. Hricko GM, et al: Factors responsible for urinary fistula in the renal transplant recipient. Ann. Surg. 178: 609 (1973).

6. Schiff $\mathrm{M} \mathrm{Jr}$, et al: Management of urinary fistulas after renal transplantation. J. Urol. 115: 251 (1976).

7. Vallely JF it al: Spontameous rupture of the renal pelvis: complication of renal homotransplantation, J. Urol. 116: 253 (1976)

8. Malek CH. it al: Urological complications of renal trans plantation, ihid. 109: 173 (1973). 